Review

\title{
Pneumocystis Species Co-evolution: State-of-the-Art Review
}

\author{
Christine Demanche ${ }^{1}$, Jacques Guillot ${ }^{2}$, Magali Chabé ${ }^{1, *}$
}

1. Univ. Lille, CNRS, Inserm, CHU Lille, Institut Pasteur de Lille, U1019-UMR 8204-CIIL-Centre d'Infection et d'Immunité de Lille, Lille, France; E-Mails: christine.demanche@univ-lille.fr; magali.chabe@univ-lille.fr

2. EA 7380 Dynamyc, USC ANSES, Université Paris-Est Créteil, Créteil, France \& Unité de Parasitologie-Mycologie, Ecole nationale vétérinaire d'Alfort, Maisons-Alfort, France; E-Mail: jacques.guillot@vet-alfort.fr

* Correspondence: Magali Chabé; magali.chabe@univ-lille.fr

Academic Editors: Andrés Moya, Enrique J. Calderón and Luis Delaye

Special Issue: Pneumocystis: A Model of Adaptive Coevolution

OBM Genetics

2019 , volume 3 , issue 2

doi:10.21926/obm.genet.1902078
Received: February 22, 2019

Accepted: May 07, 2019

Published: May 15, 2019

\begin{abstract}
Pneumocystis spp. are a group of fungi that are known for causing opportunistic infections in immunocompromised individuals. It was only at the end of the 20th century that the scientific community challenged the notion of a unique species in the genus Pneumocystis (i.e., Pneumocystis carinii) that drastically changed the understanding of the natural history of pneumocystosis. It is now accepted that the Pneumocystis genus comprises a group of heterogenous fungi having multiple stenoxenic biological entities. These are widely distributed in the ecosystems and closely adapt to the mammalian species they colonize. The infection is transmitted via airborne route, allowing them to successfully dwell in the lungs of infected individuals. This article reviews some of the atypical features of these fungal microorganisms, namely host specificity and their parallel history with the mammalian hosts in which they co-evolve. Pneumocystis organisms can serve as powerful tools for phylogenetic and phylogeographic studies in mammals. Finally, the review challenges the genetic markers used historically to study the genetic diversity of
\end{abstract}



(C) 2019 by the author. This is an open access article distributed under the conditions of the Creative Commons by Attribution License, which permits unrestricted use, distribution, and reproduction in any medium or format, provided the original work is correctly cited. 
Pneumocystis spp. to improve our understanding of Pneumocystis co-evolution with their hosts.

\section{Keywords}

Pneumocystis spp.; mammals; host specificity; co-evolution

\section{Pneumocystis Organisms as Stenoxenic Organisms with A Long History Parallel to that of Their Mammalian Hosts}

Advancements in the fields of phylogeny and genetics have drastically changed our understanding of the biology and evolutionary history of Pneumocystis organisms in the past 30 years. We now know that the genus Pneumocystis comprises highly diversified fungal organisms with a very high degree of host specificity [1]. Pneumocystis organisms have been detected in all mammalian species studied till date [1-6], owing to their unique mechanisms of adaptation to proliferate and survive exclusively in mammalian hosts [7-10]. Moreover, the genus consists of a group of parasitic microorganisms infecting a vast diversity of hosts in various ecosystems [2-6].

A high level of host specificity (stenoxenism) is a condition that allows cospeciation. Frenkel was the first one to describe in 1976 that rat- and human-derived Pneumocystis were different entities due to differences in their host specificity and antigenicity [11]. Therefore, he suggested a new taxonomic nomenclature for these organisms. However, his proposition to use a new specific name for human Pneumocystis organisms was not taken into consideration. An important observation that confirmed stenoxenism in these organisms was the systematic failure of crossinfection experiments [12-16]. Genomic and phenotypic divergence made possible the description of several Pneumocystis species [17-20] such that at the end of the 20th century, the unique taxonomically enigmatic entity called "Pneumocystis carinii" suddenly became a group of stenoxenic species. Another aspect of host specificity is that Pneumocystis species are mostly obligate biotrophs [9, 21-23]. Indeed, Pneumocystis organisms secrete low amounts of lytic proteases and cause little damage to their hosts. These are two hallmarks of biotrophy, where, in a parasitic relationship, the parasite obtains food from living host cells [21, 23]. Moreover, most biotrophs are obligate parasites, meaning they cannot survive without their hosts and cannot be cultured axenically in the laboratory [24]. In addition, data obtained from the genome analysis of Pneumocystis species revealed very compact genomes, suggesting that these organisms have lost several families of genes and metabolic pathways during the course of evolution, and whose products they scavenge from the lung environment of the host $[7,9,22,25,26]$. Consistently, Pneumocystis pneumonia seems to be rare in wild mammals and only low rates of Pneumocystis organisms are usually detected in their lungs [1-6].

Although several recent studies have described the existence of hybrid Pneumocystis using multiple genetic markers [27], isoenzymatic and first genetic data suggested that speciation in the Pneumocystis genus resulted from long genetic isolation and a potential co-speciation process [28, 29]. The approximate time of Pneumocystis speciation was estimated by Keely et al. [30], who examined the genetic variations at rRNA and DHFR loci between different Pneumocystis species. The speciation time was confirmed by a recent study by Cissé et al. in 2018 [10] using a different 
methodology. Accordingly, rat-derived Pneumocystis organisms diverged from the human-derived Pneumocystis approximately 90 to 100 million years ago. Interestingly, this estimation matches well with the divergence time of rodents and primates [31].

Assessing the congruence between phylogenetic trees from two groups of organisms (Pneumocystis species and mammals in the present case) is a major step to check for co-speciation. This has been performed for the first time between primates and primate-related Pneumocystis [4, $32,33]$. A global study based on the analysis of lung tissues from different kinds of mammals confirmed the results obtained in primates, i.e., Pneumocystis phylogenetic trees resemble the phylogeny of corresponding mammalian host species or groups [6]. However, as the congruence in the time of divergence has not been formally tested in these studies, it is difficult to state with certainty that the congruence of phylogenetic host and parasite trees is the result of co-speciation $[4,33]$ or host shifts events, as recently suggested $[10,34]$. Moreover, it is known that both cospeciation and host-shift speciation can result in congruent phylogenies and that co-phylogenetic methods often overestimate the occurrence of co-speciation events [35].

\section{Pneumocystis Organisms as Powerful Tools for Phylogenetic and Phylogeographic Studies in Mammalian Hosts}

A study conducted in primate-derived Pneumocystis reported specific DNA sequence divergence among Pneumocystis species to be clearly correlating with the phylogeny of their corresponding hosts [4, 33] (Figure 1). To collect original material, postmortem lung tissues from non-human primates were obtained from the French zoological parks and from the French Primate Research Center in Strasbourg, France. Additional lung tissues from wild monkeys were collected from French Guyana. The genetic diversity of Pneumocystis from primates was examined by analyzing mitochondrial large subunit ( $\mathrm{mtLSU}$ ) rRNA and dihydropteroate synthase (DHPS) gene sequences, both of which are highly conserved. Each of the 18 non-human primate species or subspecies that was proved to harbor Pneumocystis had its own type of organism with specific mtLSU rRNA or DHPS sequence (Figure 1). Furthermore, it is interesting to note that in the case of the red-handed tamarin (Saguinus midas), positive PCR amplifications were obtained from both captive and wild animals (three samples from a French zoological park, and one sample from French Guyana), and the corresponding mtLSU rRNA sequences were identical [4]. No humanderived Pneumocystis ( $P$. jirovecii) was found in non-human primate lung tissues or air samples examined. A detailed comparison of Pneumocystis and primates phylogenies was performed using TreeMap 1.0b [36] (Figure 2). The molecular phylogeny of Pneumocystis was compared with different controversial phylogenies (according to the mitochondrial and/or nuclear markers, and morphological characters that were used) for the hosts. This comparison demonstrated that depending upon which topology was accepted for the hosts, at least $61 \%$ and up to $77 \%$ of the homologous nodes of the respective cladograms of the hosts and parasites could be interpreted to result from co-divergence events [33]. 

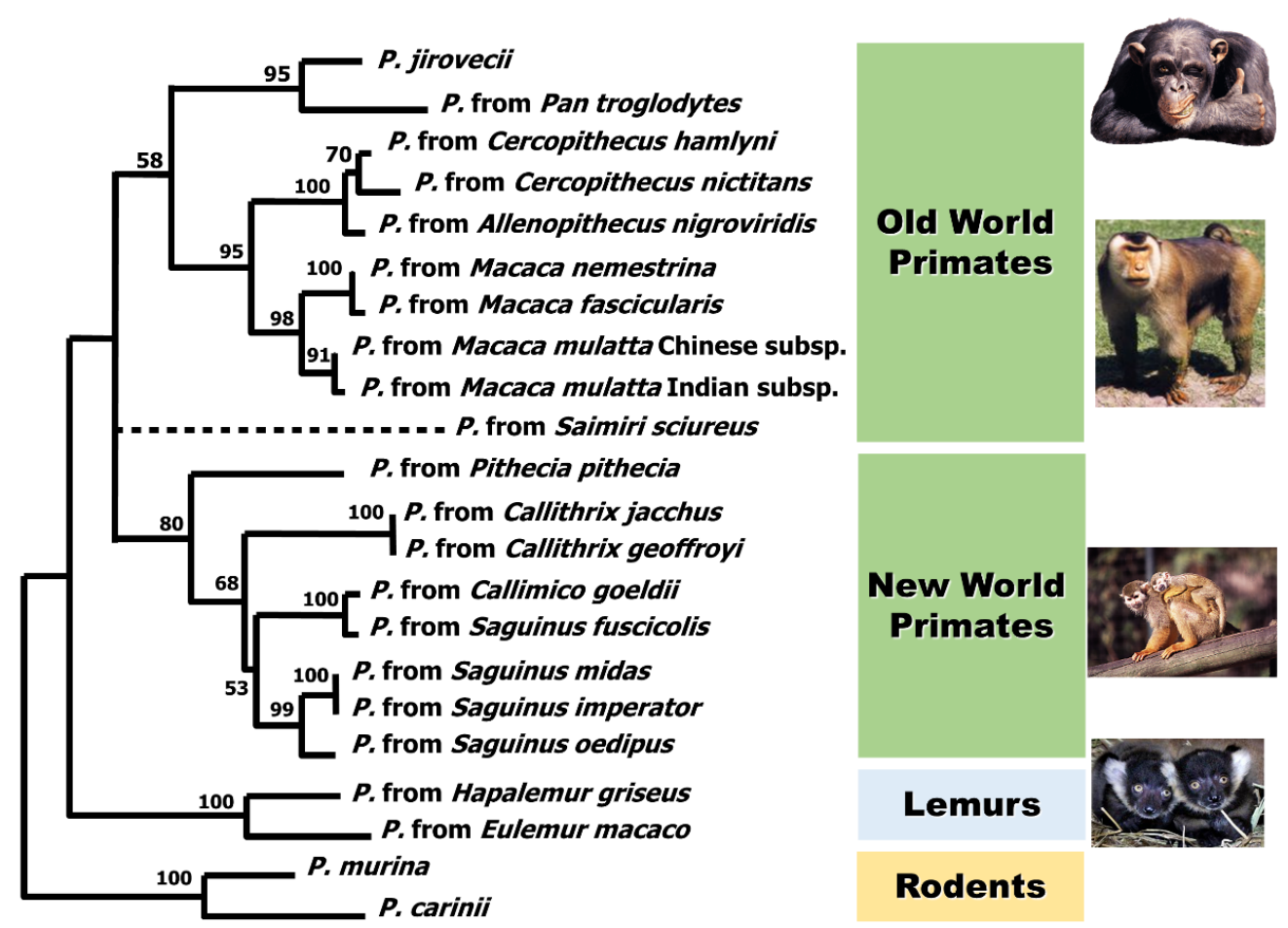

Figure 1 Phylogenetic tree of Pneumocystis mtLSU rRNA sequences obtained from 19 non-human primate species (from Demanche et al., 2001).

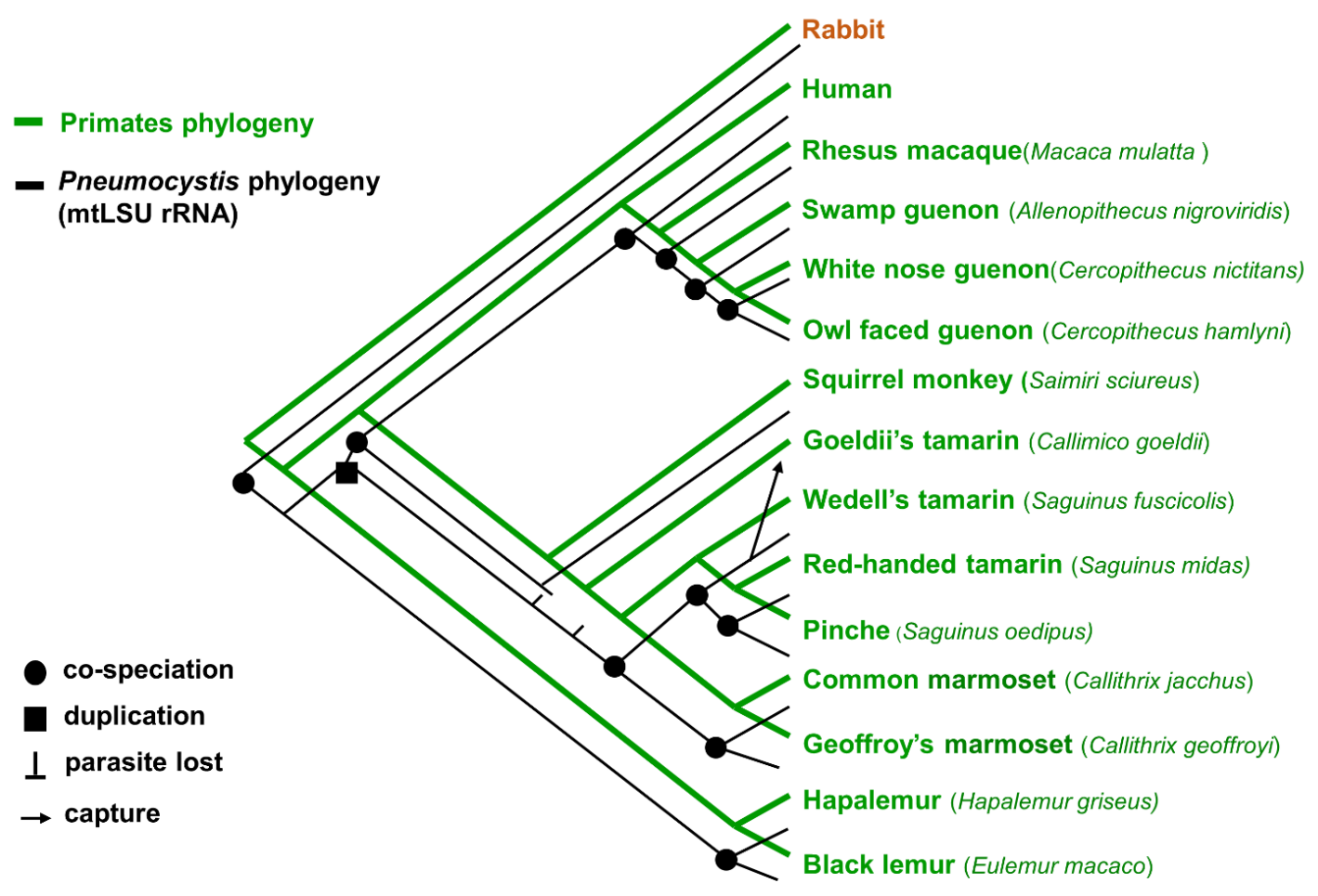

Figure 2. Comparison of Pneumocystis and primate's phylogenies with TreeMap 1.0b (from Demanche, 2003). 
The phenomenon of co-speciation was also reported in bats. This group of mammals is particularly interesting because of its high biodiversity, in terms of species and ecological characteristics. Bats are widely distributed in various ecosystems and constitute one of the largest groups of mammals, second in the number of species after rodents and first in the number of individuals [37]. The genetic diversity of Pneumocystis was studied in lung samples from 19 bat species that were collected from diverse biotopes in New and Old Worlds [2]. Pneumocystis was detected by nested PCR at both mtLSU and mitochondrial small subunit (mtSSU) rRNA loci. This study yielded valuable information on Pneumocystis biology and transmission. Indeed, ecological and behavioral factors (elevation, crowding, and migration) seemed to influence the Pneumocystis carriage. Eleven bat species belonging to five families were found to harbor Pneumocystis DNA. For each bat species carrying Pneumocystis DNA, at least one novel sequence was amplified at one and/or both loci, suggesting that each species of bats could be harboring a specific species of Pneumocystis. Similarly, the data showed that genetic divergence in bat-derived Pneumocystis organisms paralleled the phylogenetic divergence existing among corresponding hosts, Pneumocystis phylogeny mirrored its host phylogeny, also suggesting co-evolution (Figure 3). Moreover, the link between genetic variability of Pneumocystis isolated from populations of the same migrating bat species Tadarida brasiliensis and their geographical area could be exploited in terms of phylogeography $[2,38]$. In this case, Pneumocystis species genotypes were used as proxies at the phylogeographical scale.

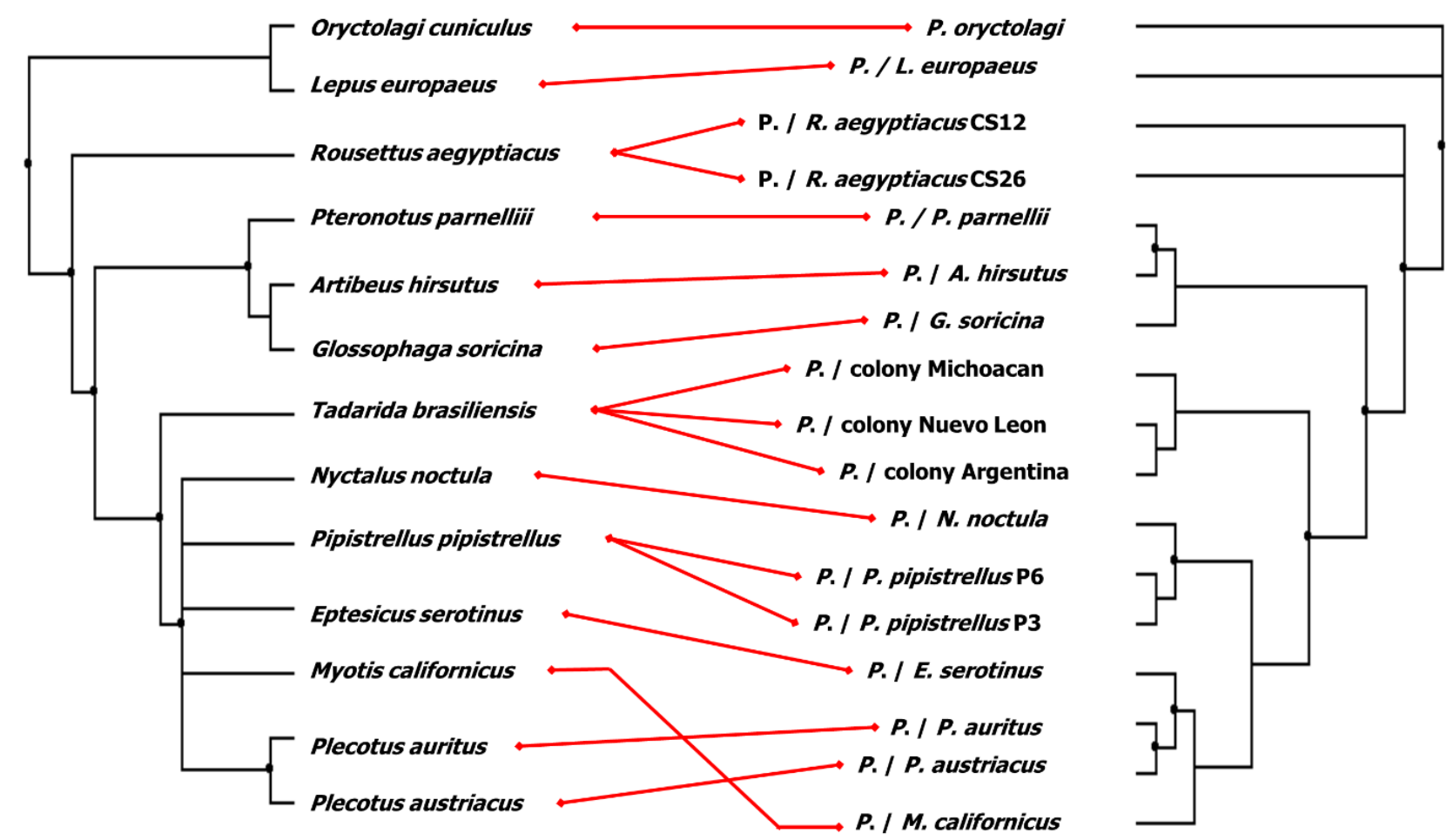

Host-tree

Pneumocystis-tree

Figure 3 Parallel phylogenies of Pneumocystis mtSSU rRNA sequences and their bat hosts (from Derouiche et al., 2009). 
Similar findings were obtained at the Pneumocystis infra-specific level for Apodemus sylvaticus, the common wood mouse [5]. The presence of Pneumocystis DNA was assessed by nested PCR at mtLSU and mtSSU rRNA loci. The results demonstrated a very high variability among wood mousederived Pneumocystis organisms with a total number of 30 distinct combined mtLSU and mtSSU sequence types. However, the genetic divergence among these sequence types was very low (less than 3.9\%), and the presence of several Pneumocystis species within A. sylvaticus was considered unlikely. The analysis of the genetic structure of wood mouse-derived Pneumocystis revealed two distinct groups: the first group comprised Pneumocystis from wood mice collected from continental Spain, France, and the Balearic Islands, and the second group included Pneumocystis from wood mice collected from continental Italy, Corsica, and Sicily. These two genetic groups were in accordance with the two lineages currently described within the host species $A$. sylvaticus. Pneumocystis DNA polymorphism seems to be related to the geographical distribution of wood mice, and the analysis of Pneumocystis genetic diversity is thus in agreement with the evolutionary history of $A$. sylvaticus in Europe. Pneumocystis organisms are known to be possibly carried by their specific hosts during their migration and evolution [5]. Many micro-organisms can be used as a proxy at a phylogenetic or phylogeographical scale to gain insights into the host phylogeny or migrations [39-43]. However, to our knowledge, Pneumocystis is the only organism that can simultaneously serve as a good phylogeographical and evolutionary marker for its hosts.

\section{Some Exceptions that Prove the Rule}

Till date, only five Pneumocystis species have been formally described and accepted based on the requirements of the International Code of Botanical Nomenclature (ICBN). Pneumocystis jirovecii [11] is present in humans; P. oryctolagi [18] has been described in rabbits (Oryctolagus cuniculus); P. murina [19] is the sole species described in laboratory mice (Mus musculus), whereas two species have been described in the laboratory rats (Rattus norvegicus), namely $P$. carinii [20] and $P$. wakefieldiae [17].

In order to determine whether the strains of Pneumocystis infecting wild rats differ from those in laboratory rats and thus avoid biases derived from conventional breeding, a study looked for Pneumocystis spp. that could be encountered in wild rats (R. norvegicus) in Thailand. Pneumocystis DNA was detected in $57.7 \%$ of these animals, although the presence of Pneumocystis organisms was never associated with typical Pneumocystis pneumonia [3]. The two Pneumocystis species $P$. carinii and $P$. wakefieldiae were found in wild rats from Thailand. $P$. carinii and $P$. wakefieldiae were found alone in $19 \%$ and $23 \%$ of rats, respectively, and $7.7 \%$ of the rats were colonized by both species. In this work, a new variant sequence of $P$. wakefieldiae was also identified in wild rats in the same geographical area [3].

Interestingly, Southeast Asia is considered to be the center of origin and diversification of Murinae rodents, from where they have been known to spread to other parts of the Old World [44]. Murid rodents belong to the most diverse mammalian family (Muridae) and comprise over 700 species [45]. In addition, they occupy a wide range of ecological niches in diverse habitats, ranging from cities to agricultural fields and primary forests. Thus, due to their high taxonomical and ecological diversity and the high prevalence of Pneumocystis described in wild rodents [3, 5, $28,29,46,47]$, murid rodents in Southeast Asia are considered to be extremely relevant models for understanding the evolutionary interactions of Pneumocystis species and their mammalian 
hosts. This was precisely the subject of a recently published study [34], in which the genetic diversity and host specificity of Pneumocystis organisms infecting wild Southeast Asian murid rodents was investigated through PCR sequencing of two mitochondrial genes (mtLSU rRNA and mtSSU rRNA) followed by checking the co-phylogeny hypothesis among Pneumocystis spp./ strains and their rodent hosts. Pneumocystis organisms were detected in 48.3\% (215/445) of these wild rodents belonging to 18 Southeast Asian murid species and 8 genera [34]. In total, 69 distinct Pneumocystis sequence types were identified for mtLSU rRNA and 43 for mtSSU rRNA. Interestingly, some Pneumocystis sequence types could be shared between several host species and genera. For example, although most sequence types of two loci were specific to a murid species, it was surprising to observe that $7 \mathrm{mtLSU}$ rRNA sequence types were common to several Rattus species or were found in two Berylmys species. Similarly, of the 43 types of mtSSU rRNA sequences identified, 4 were common to several Rattus species or shared between Maxomys surifer and Leopoldamys herberti. It should be noted that these types of shared sequences have been isolated at different time points and in different locations, thus confirming the relevance of these results. Also, the three Pneumocystis species already described in rats and mice can infect several rodent species. $P$. murina can be recovered from the lungs of various species of the Mus genus, and both $P$. carinii and $P$. wakefieldiae can be found alone or together in the lungs of various Rattus species. Co-phylogenetic analyses revealed a complex evolutionary history among Pneumocystis species/lineages and their rodent hosts. Even if a significant global co-speciation signal has been detected, it is alone insufficient to explain the observed co-phylogenetic pattern, suggesting that several host switches have probably occurred. These results, therefore, suggest a lower host specificity of Pneumocystis species than what was previously thought in rodents.

The lower host specificity of Pneumocystis species/lineages colonizing wild rodents than that of primates and bats could be attributed to similarities in physiological, cellular architecture, and/or immune systems among these closely related rodent species that diverged quite recently. Indeed, the origin of the Rattus genus, that contains 66 species [45], is relatively recent, estimated at approximately 2 to 3 million years, and its diversification rate is more than three times higher than that for other Murinae rodents [48], suggesting that these rodents are still in the process of speciation.

In the coevolution theory, parasites infecting micromammals (small-bodied with short lifespans, high reproduction rates, and high population densities) have lower host specificity than those adapted to long-lived hosts with more stable population densities [49]. It is interesting to note that humans are infected by only one Pneumocystis species, whereas wild rats, according to the results mentioned above, may be co-infected by two or more Pneumocystis species [3, 34]. These results may indicate a relaxation of strict host specificity in small mammals colonized by these fungi.

Another exception regarding the strong host specificity of Pneumocystis has been reported in macaques. The circulation of Pneumocystis organisms within a social organization of healthy crabeating macaques (Macaca fascicularis) living in a natural setting in France was studied for two years with biological samples collected monthly [50]. Pneumocystis DNA was detected every month in several animals within the colony. The study demonstrated a relatively high prevalence of Pneumocystis DNA in the upper respiratory tract of healthy macaques (33.6\% of PCR-positive nasal swabs). Moreover, the presence of Pneumocystis DNA was frequently detected from nasal swab samples by nested PCR at mtLSU and mtSSU rRNA loci throughout the study. The fungi are 
always aerially transmitted; the transmission being favored by co-housing with transiently infected healthy animals. Specific Pneumocystis DNA sequence types were harbored by M. fascicularis. No Pneumocystis from other primate species including humans was found despite co-housing with other primate species. However, it is important to note that one sequence type was common to samples from Macaca mulatta and Macaca fascicularis from the same research center. Three nasal swab samples from three different individuals of the Macaca fascicularis colony and one Macaca mulatta lung tissue sample were similar [51]. A study about phylogenetic relationships among Pneumocystis from Asian macaques using mitochondrial rRNA sequences demonstrated that two genetic macaque-derived groups could be considered as distinct Pneumocystis species. Surprisingly, these Pneumocystis species were recovered from both M. mulatta and M. fascicularis. The lack of host specificity in macaque-derived Pneumocystis could be explained by the hypothesis that the rhesus and crab-eating macaques belong to the same entity (maybe species?) or that they have not speciated completely and are still in the process of speciation like murid rodents from South Asia. This hypothesis is strongly supported by several investigations related to the classification of the genus Macaca and the possibility of natural hybridization between the rhesus and crab-eating macaques [52-55]. The divergence time between the two species is also very recent and has been estimated to be 1.3 million years [55].

The last example challenges the strict stenoxenism of Pneumocystis at the host intra-generic level. Indeed, an identical Pneumocystis lineage (based on mtLSU rRNA sequence) was found in the lungs of Apodemus flavicollis and A. sylvaticus [46].

\section{Challenging mtLSU and mtSSU rRNA Genetic Markers to Study Pneumocystis Genetic Diversity}

Only two mitochondrial genes, i.e., mtLSU and mtSSU rRNAs have been historically used in all epidemiological and phylogenetically related studies to explore the genetic diversity of Pneumocystis in mammals. To strengthen and confirm the obtained results, additional markers such as nuclear genes (found in a single copy in Pneumocystis genomes) could be used; these could also confirm the hypothesis for Pneumocystis species delineation and co-speciation. However, it should be kept in mind that wild animals carry very low fungal load in their lungs, i.e., they usually do not develop Pneumocystis pneumonia [3] and that the amplification of single-copy genes could be problematic. To overcome the difficulty of obtaining the sufficient quantity of Pneumocystis micro-organisms and high purity of genomic DNA for genome sequencing, two approaches, namely purification of parasites and a Whole Genome Amplification (WGA) before next-generation sequencing (NGS), could be implemented. One of the major problems encountered is the removal of host cells and DNA in the purification step, a problem that was also faced by several authors while sequencing Pneumocystis genomes [7, 10, 26, 56, 57]. However, Martinez et al. [58] described an original, reproducible, and efficient method for separating trophic and cystic forms of $P$. carinii using a high-speed cell sorter. Large amounts of highly purified (99.6 $\pm 0.3 \%$ ) Pneumocystis trophic and cystic forms were thus obtained. Therefore, combining this purification approach with a WGA of Pneumocystis organisms present in the lungs of wild mammals would certainly be a good approach to sequence these Pneumocystis genomes.

Moreover, reports on mitochondrial gene dynamics during $P$. jirovecii infection have shown Pneumocystis mitochondrial genomes to be significantly plastic in terms of variation in copy number [59] and genetic diversity, including heteroplasmy [60]. Thus, the interpretation of results 
of Sanger sequencing from lung samples of these infected rodents could be questioned. Indeed, Sanger sequencing is not the optimal method for identifying mixed Pneumocystis infections owing to its inability to detect minority alleles. Application of other methods such as NGS would make it possible to overcome this shortcoming and to study precisely Pneumocystis co-infection patterns in animals.

\section{Author Contributions}

$M C, C D$ and JG contributed equally to this work.

\section{Competing Interests}

The authors have declared that no competing interests exist.

\section{References}

1. Aliouat-Denis $C M$, Chabé $M$, Demanche $C$, Aliouat EM, Viscogliosi E, Guillot J, et al. Pneumocystis species, co-evolution and pathogenic power. Infect Genet Evol. 2008; 8: 708726.

2. Akbar $\mathrm{H}$, Pinçon $\mathrm{C}$, Aliouat $\mathrm{CM}$, Derouiche $\mathrm{S}$, Taylor $\mathrm{ML}$, Pottier $\mathrm{M}$, et al. Characterizing Pneumocystis in the lungs of bats: understanding Pneumocystis Evolution and Spread of Pneumocystis organisms in mammal populations. Appl Environ Microbiol. 2012; 78: 81228136.

3. Chabé M, Herbreteau V, Hugot JP, Bouzard N, Deruyter L, Morand S, et al. Pneumocystis carinii and Pneumocystis wakefieldiae in wild Rattus norvegicus trapped in Thailand. J Eukaryot Microbiol. 2010; 57: 213-217.

4. Demanche C, Berthelemy M, Petit T, Polack B, Wakefield AE, Dei-Cas E, et al. Phylogeny of Pneumocystis carinii from 18 primate species confirms host specificity and suggests coevolution. J Clin Microbiol. 2001; 39: 2126-2133.

5. Demanche C, Deville M, Michaux J, Barriel V, Pinçon C, Aliouat-Denis CM, et al. What do Pneumocystis organisms tell us about the phylogeography of their hosts? The case of the woodmouse Apodemus sylvaticus in continental Europe and western Mediterranean islands. PLoS One. 2015; 10: e0120839. Erratum in: PLoS One. 2017; 12: e0171282.

6. Guillot J, Demanche C, Hugot JP, Berthelemy M, Wakefield AE, Dei-Cas E, et al. Parallel phylogenies of Pneumocystis species and their mammalian hosts. J Euk Microbiol. 2001; Suppl: 133-115.

7. Ma L, Chen Z, Huang da W, Kutty G, Ishihara M, Wang H, et al. Genome analysis of three Pneumocystis species reveals adaptation mechanisms to life exclusively in mammalian hosts. Nat Commun. 2016; 22: 10740.

8. Ma L, Cissé OH, Kovacs JA. A Molecular Window into the Biology and Epidemiology of Pneumocystis spp. Clin Microbiol Rev. 2018; 31. pii: e00009-18

9. Hauser PM, Burdet FX, Cisse OH, Keller L, Taffe P, Sanglard D, Pagni M. Comparative genomics suggests that the fungal pathogen pneumocystis is an obligate parasite scavenging amino acids from its host's lungs. Plos One. 2010; 5: e15152.

10. Cissé $\mathrm{OH}, \mathrm{Ma}$ L, Wei Huang D, Khil PP, Dekker JP, Kutty G, et al. comparative population 
genomics analysis of the mammalian fungal pathogen pneumocystis. MBio. 2018; 9. pii: e00381-18.

11. Frenkel JK. Pneumocystis jiroveci n. sp. from man: Morphology, physiology, and immunology in relation to pathology. Natl Cancer Inst Monogr. 1976; 43: 13-30.

12. Aliouat E, Mazars E, Dei-Cas E, Cesbron J, Camus D. Intranasal inoculation of mouse, rat or rabbit-derived Pneumocystis in SCID mice. J Protozool Res. 1993 ; 3: 94-98.

13. Aliouat EM, Mazars E, Dei-Cas E, Delcourt P, Billaut P, Camus D. Pneumocystis cross infection experiments using SCID mice and nude rats as recipient host, showed strong host-species specificity. J Eukaryot Microbiol. 1994; 41: 71S.

14. Atzori C, Agostoni F, Angeli E, Mainini A, Micheli V, Cargnel A. P. carinii host specificity: Attempt of cross infections with human derived strains in rats. J. Eukaryot. Microbiol. 1999; 46: $112 S$.

15. Durand-Joly I, Aliouat EM, Recourt C, Guyot K, Francois N, Wauquier M, et al. Pneumocystis carinii f. sp. hominis is not infectious for SCID mice. J Clin Microbiol. 2002; 40: 1862-1865.

16. Gigliotti F, Harmsen AG, Haidaris PJ. Pneumocystis carinii is not universally transmissible between mammalian species. Infect Immun. 1993; 61: 2886-2890.

17. Cushion MT, Keely SP, Stringer JR. Molecular and phenotypic description of Pneumocystis wakefieldiae sp. nov., a new species in rats. Mycologia. 2004; 96: 429-438.

18. Dei-Cas E, Chabé M, Moukhlis R, Durand-Joly I, Aliouat el M, Stringer JR, et al. Pneumocystis oryctolagi sp. nov., an uncultured fungus causing pneumonia in rabbits at weaning: Review of current knowledge and description if a new taxon on genotypic, phylogenetic and phenotypic bases. FEMS Microbiol Rev. 2006; 30:853-871.

19. Keely SP, Fischer JM, Cushion MT, Stringer JR. Phylogenetic identification of Pneumocystis murina sp. nov., a new species in laboratory mice. Microbiology. 2004; 150: 1153-1165.

20. Frenkel, J. Pneumocystis pneumonia, an immunodeficiency-dependent disease (IDD): a critical historical overview. J Eukaryot Microbiol. 1999; 46, S89-S92.

21. Cissé $\mathrm{OH}$, Hauser PM. Genomics and evolution of Pneumocystis species. Infect Genet Evol. 2018; 65: 308-320.

22. Cissé $\mathrm{OH}$, Pagni $\mathrm{M}$, Hauser PM. Comparative genomics suggests that the human pathonic fungus Pneumocystis jirovecii acquired obligate biotrophy through gene loss. Genome Biol Evol. 2014; 6: 1938-1948.

23. Hauser PM. Genomic insights into the fungal pathogens of the genus Pneumocystis: Obligate biotrophs of humans and other mammals. PLo S Pathogens. 2014; 10: e1004425.

24. Kemen E, Jones JD. Obligate biotroph parasitism: can we link genomes to lifestyles? Trends Plant Sci. 2012; 17: 448-457.

25. Vestereng $\mathrm{VH}$, Kovacs JA. Inability of Pneumocystis organisms to incorporate bromodeoxyuridine suggests the absence of a salvage pathway for thymidine. Microbiology. 2004; 150: 1179-1182.

26. Cissé OH, Pagni M, Hauser PM. De novo assembly of the Pneumocystis jirovecii genome from a single bronchoalveolar lavage fluid specimen from a patient. MBio. 2012; 4: e00428-12.

27. Goüy de Bellocq J, Wasimuddin, Ribas A, Bryja J, Piálek J, Baird SJE. Holobiont suture zones: Parasite evidence across the European house mouse hybrid zone. Mol Ecol. 2018; 27: 52145227.

28. Mazars E, Guyot K, Durand I, Dei-Cas E, Boucher S, Ben Abderrazak S, et al. Isoenzyme 
diversity in Pneumocystis carinii from rats, mice and rabbits. J Infect Dis. 1997; 175: 655-660.

29. Mazars E, Dei-Cas E. Epidemiological and taxonomic impact of Pneumocystis biodiversity. FEMS Immunol Med Microbiol. 1998; 22: 75-80.

30. Keely SP, Fischer JM, Stringer JR. Evolution and speciation of Pneumocystis. J Eukaryot Microbiol. 2003; 50: 624S-626S.

31. Nei M, Xu P, Glazko G. Estimation of divergence times from multiprotein sequences for a few mammalian species and several distantly related organisms. Proc Natl Acad Sci USA. 2001; 98 : 2497-2502.

32. Demanche, C. Genetic variability and circulation of Pneumocystis in non-human primates populations. PhD thesis. Paris: Université Paris XII; 2003.

33. Hugot JP, Demanche C, Barriel V, Dei-Cas E, Guillot J. Phylogenetic systematics and evolution of primate-derived Pneumocystis based on mitochondrial or nuclear DNA sequence comparison. Syst Biol. 2003; 52: 735-744.

34. Latinne A, Bezé F, Delhaes L, Pottier M, Gantois N, Nguyen J, et al. Genetic diversity and evolution of Pneumocystis fungi infecting wild Southeast Asian murid rodents. Parasitology. 2018; 145: 885-900.

35. de Vienne DM, Refrégier G, López-Villavicencio M, Tellier A, Hood ME, Giraud T. Cospeciation vs host-shift speciation: methods for testing, evidence from natural associations and relation to coevolution. New Phytol. 2013; 198: 347-385.

36. Page RDM. Parallel phylogenies: reconstructing the history of host-parasite assemblages. Cladistics. 1995; 10: 155-173.

37. Nowak RM. Walker's mammals of the world. 6th ed. Baltimore: The John Hopkins University Press; 1999. pp. 253-489.

38. Derouiche S, Deville M, Taylor ML, Akbar H, Guillot J, Carreto-Binaghi LE et al. Pneumocystis as phylogeographic markers? Mem Instit Oswaldo Cruz. 2009; 104: 112-117.

39. Bruyndonckx N, Biollaz F, Dubey S, Goudet J, Christe P. Mites as biological tags of their hosts. Mol Ecol. 2010; 19: 2770-2778.

40. Criscione CD, Cooper B, Blouin MS. Parasite genotypes identify source populations of migratory fish more accurately than fish genotypes. Ecology. 2006; 87: 823-828.

41. Nieberding CM, Olivieri I. Parasites: proxies for host genealogy and ecology? Trends Ecol Evol. 2007; 22: 156-165.

42. Nieberding CM, Durette-Desset MC, Vanderpoorten A, Casanova JC, Ribas A, Deffontaine V, et al. Geography and host biogeography matter for understanding the phylogeography of a parasite. Mol Phylogenet Evol. 2008; 47: 538-554.

43. Megía-Palma R, Martínez J, Cuervo JJ, Belliure J, Jiménez-Robles O, Gomes V, et al. Molecular evidence for host-parasite co-speciation between lizards and Schellackia parasites. Int J Parasitol. 2018; 48: 709-718.

44. Schenk JJ, Rowe KC, Steppan SJ. Ecological opportunity and incumbency in the diversification of repeated continental colonizations by muroid rodents. Syst Biol. 2013; 62: 837-864.

45. Musser GG, Carleton M. Mammal species of the world: A taxonomic and geographic reference. Baltimore: Johns Hopkins University Press; 2005. pp. 894-1531.

46. Danesi P, da Rold G, Rizzoli A, Hauffe HC, Marangon S, Samerpitak K, et al. Barcoding markers for Pneumocystis species in wildlife. Fungal Biol. 2016; 120: 191-206.

47. Palmer RJ, Settnes OP, Lodal J, Wakefield AE. Population structure of rat-derived 
Pneumocystis carinii in Danish wild rats. Appl Environ Microbiol. 2000; 66: 4954-4961.

48. Rowe KC, Aplin KP, Baverstock PR, Moritz C. Recent and rapid speciation with limited morphological disparity in the genus Rattus. Syst Biol. 2011; 60: 188-203.

49. Poulin R. Micromammals and macroparasites: From evolutionary ecology to management. Tokyo: Springer-Verlag; 2006.

50. Demanche C, Wanert F, Barthélemy M, Mathieu J, Durand-Joly I, Dei-Cas E, et al. Molecular and serological evidence of Pneumocystis circulation in a social organization of healthy macaques (Macaca fascicularis). Microbiology. 2005; 151: 3117-3125.

51. Guillot J, Demanche C, Norris K, Wildschutte H, Wanert F, Berthelemy M, et al. Phylogenetic relationships among Pneumocystis from Asian macaques inferred from mitochondrial rRNA sequences. Mol Phylogenet Evol. 2004; 31: 988-996.

52. Fooden, J. The Macaques: Studies in ecology, behavior and evolution. New York: Van NostrandReinhold; 1980. pp. 1-9.

53. Bernstein IS, Gordon TP. The Macaques: Studies in ecology, behavior and evolution. New York: Van Nostrand-Reinhold; 1980. pp. 125-147.

54. Tosi AJ, Morales JC, Melnick DJ. Comparison of $Y$ chromosome and mtDNA phylogenies leads to unique inferences of macaque evolution history. Mol Phylogenet Evol. 2000; 17: 133-144.

55. Stevison LS, Kohn MH. Divergence population genetic analysis of hybridization between rhesus and cynomolgus macaques. Mol Ecol. 2009; 18: 2457-2475.

56. Cushion MT, Smulian AG, Slaven BE, Sesterhenn T, Arnold J, Staben C, Porollo A, Adamczak R, Meller J. Transcriptome of Pneumocystis carinii during fulminate infection: carbohydrate metabolism and the concept of a compatible parasite. PLoS One. 2007; 2: e423.

57. Slaven BE, Meller J, Porollo A, Sesterhenn T, Smulian AG, Cushion MT. Draft assembly and annotation of the Pneumocystis carinii genome. J Eukaryot Microbiol. 2006; 53: S89-91.

58. Martinez A, Aliouat EM, Pottier M, Gantois N, Pinçon C, Standaert-Vitse A, et al. High-speed cell sorting of infectious trophic and cystic forms of Pneumocystis carinii. J Eukaryot Microbiol. 2009; 56: 446-453.

59. Valero C, Buitrago MJ, Gits-Muselli M, Benazra M, Sturny-Leclère A, Hamane S, et al. Copy number variation of mitochondrial DNA genes in Pneumocystis jirovecii according to the fungal load in BAL specimens. Front Microbiol. 2016; 12: 1413.

60. Alanio A, Gits-Muselli M, Mercier-Delarue S, Dromer F, Bretagne S. Diversity of Pneumocystis jirovecii during infection revealed by ultra-deep pyrosequencing. Front Microbiol. 2016; 24: 733. 


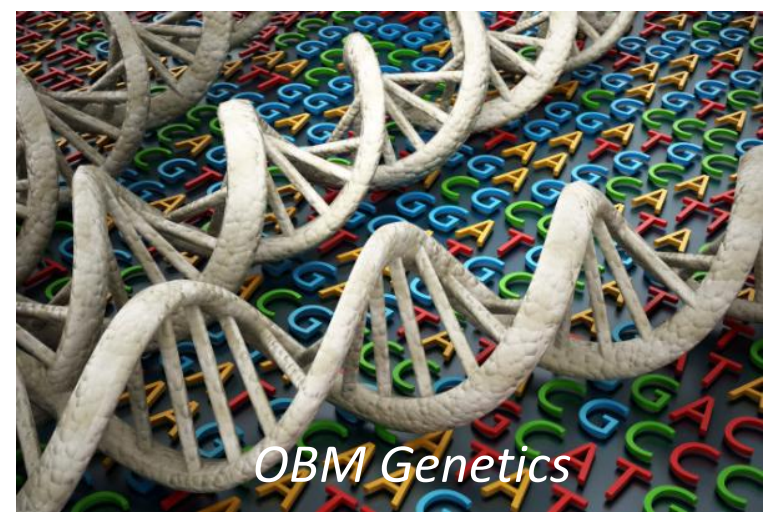

Enjoy OBM Genetics by:

1. Submitting a manuscript

2. Joining in volunteer reviewer bank

3. Joining Editorial Board

4. Guest editing a special issue

For more details, please visit:

http://www.lidsen.com/journals/genetics 